\title{
Endocrine-metabolic Adaptations in Dorper Ewes: Comparison Between Single and Twin Pregnancies During Gestation, Delivery, and Postpartum
}

Bianca Paola Santarosa ( $\sim$ biancasantarosavet@gmail.com )

Universidade Federal dos Vales do Jequitinhonha e Mucuri https://orcid.org/0000-0003-0937-1919

Danilo Otávio Laurenti Ferreira

Universidade Estadual Paulista Julio de Mesquita Filho - Campus de Botucatu

Henrique Barbosa Hooper

Universidade de São Paulo Câmpus de Pirassununga: Universidade de Sao Paulo Campus Fernando Costa

\section{Yuri Karen Sinzato}

UNESP FMB: Universidade Estadual Paulista Julio de Mesquita Filho Faculdade de Medicina Campus de Botucatu

\section{Débora Cristina Damasceno}

UNESP FMB: Universidade Estadual Paulista Julio de Mesquita Filho Faculdade de Medicina Campus de Botucatu

\section{Daniel Montanher Polizel}

ESALQ-USP: Universidade de Sao Paulo Escola Superior de Agricultura Luiz de Queiroz

\section{Eduardo Gorzoni Fioratti}

UFVJM: Universidade Federal dos Vales do Jequitinhonha e Mucuri

\section{Vítor Hugo dos Santos}

UEL: Universidade Estadual de Londrina

\section{Andreza Amaral da Silva}

UFRRJ: Universidade Federal Rural do Rio de Janeiro

\section{Roberto Calderon Gonçalves}

Universidade Estadual Paulista Julio de Mesquita Filho - Campus de Botucatu

\section{Research Article}

Keywords: blood glucose, cortisol, glucagon, HOMA IR, insulin, thyroid hormones

Posted Date: October 18th, 2021

DOI: https://doi.org/10.21203/rs.3.rs-936192/v1 
License: (c) (i) This work is licensed under a Creative Commons Attribution 4.0 International License. Read Full License 


\section{Abstract}

The present study involved a blood glucose, hormonal profile, and insulin resistance evaluation in sheep from conception until $48 \mathrm{~h}$ postpartum. A total of 60 healthy Dorper ewes, raised under semi-intensive management were included in the study. Two experimental groups were applied: $\mathrm{G} 1$, single pregnancy ( $\mathrm{n}$ $=30)$ and $G 2$, twin pregnancy $(n=30)$. The experimental time points were immediately after fixed-time artificial insemination; at $30 \mathrm{~d}, 90 \mathrm{~d}, 120 \mathrm{~d}, 130 \mathrm{~d}$, and $140 \mathrm{~d}$ of pregnancy; on the delivery day (DD); and at $24 \mathrm{~h}$ (PD1) and $48 \mathrm{~h}$ (PD2) postpartum. Blood samples were taken to analyse glucose, insulin, glucagon, cortisol, thyroid hormones (T3 and T4) levels. All parameters showed significant differences over the analysed sample times; however, only cortisol showed differences within groups, with the G1 having higher values than the $\mathrm{G} 2$ group. The interaction of the groups in the nine sample times showed a significant result $(P=0.001)$ only for glucagon. The number of foetuses directly interfered with the glucagon profile throughout gestation and insulin concentration postpartum. The glucose, cortisol, insulin, glucagon, and HOMA IR concentrations increased at DD and decreased at PD1 and PD2. T3 and T4 levels increased at DD. Despite the changes found in the endocrine system and metabolism in Dorper ewes throughout pregnancy, the nutritional management ensured a healthy status during pregnancy, delivery, and postpartum.

\section{Introduction}

Pregnancy is an important stage in sheep production, with metabolic, physiological, and anatomical adaptations occurring that ensure proper foetal development and survival. Metabolic adaptations during the gestational period are necessary; however, they are more pronounced during the final third stage due to higher foetal growth and mammary gland development, resulting in an increase in nutritional requirements. Any imbalance in nutrient demand and supply during this period might compromise female health and production (Caldeira et al. 2007; Celi et al. 2008; Kalyesubula et al. 2020).

Energy and hormonal profiles are valuable tools to evaluate body adaptations, metabolic disorders, and nutritional imbalances (Vernon et al. 2005). Age, breed, sex, and physiological state (Araújo et al. 2014; Kalyesubula et al. 2020) are factors that might alter the concentrations of biochemical constituents. A set of variables indicating early homeostasis imbalance can trigger metabolic disorders, mainly during the final gestation stage and in twin gestation (Araújo et al. 2014). During this stage, in pregnant goats and ewes, the most common disease is pregnancy toxaemia (PT), which has a high mortality rate (Santos et al. 2011).

Physiologically, three weeks before and after delivery, there is a reduction in insulin sensitivity, also named insulin resistance (IR) (Regnault et al. 2004), which can worsen under nutritional imbalance conditions and accumulated body fat at delivery (Oikawa and Oetzel 2006). This condition is associated with high plasma concentrations of non-esterified fatty acids (NEFA) and negative energetic balance (NEB) and has been proposed as a risk factor for metabolic diseases. PT and hypocalcaemia in sheep, 
similar to humans, show different IR intensities associated with metabolic syndromes (Schlumbohm and Harmeyer 2003; Husted et al. 2008; Schmitt et al. 2012; Duehlmeier et al. 2013; Kalyesubula et al. 2019).

In addition to insulin and glucagon (insulin-antagonist), somatotropic axis hormones, including the growth hormone, IGF-1, and thyroid hormones (T3 and T4), are the major determinants of basal metabolism, and the deposition or secretion of nutrients (Schmitt et al. 2012; Sadegzadeh-Sadat et al. 2021). The homeostatic model assessment for IR (HOMA IR) (Kalyesubula et al. 2020) and $\beta$-cell activity (HOMA $\beta$ ) were developed to evaluate insulin sensitivity and $\beta$-cell activity, respectively, using only insulinemia and blood glucose values after fasting because insulin and glucose concentrations at the basal state are determined by feedback (Vasques et al. 2008). Previous studies using sheep as a model to understand obesity in humans have been undertaken (Duckett et al. 2014); however, there is limited information regarding the application of HOMA IR in pregnant ewes. Kalyesubula et al. (2020) applied HOMA IR and showed that sheep could be used as a model for fatty liver and metabolic comorbidities arising from excess carbohydrate-based energy early in life and was related to PT occurrence.

Although many physiological changes occur close to and after parturition, there is limited information regarding the hormonal and metabolic variations between single and twin pregnancies. Hence, the present study aimed to evaluate endocrine-metabolic changes to establish the HOMA IR of pregnant Dorper ewes throughout pregnancy, delivery, and immediate postpartum time points and compare single and twin pregnancies.

\section{Materials And Methods}

\section{Experimental design}

The ewes included in the present study belonged to the Araí \& Zumbi sheep farm, located in Pardinho, São Paulo State, Brazil. A total of 150 non-pregnant healthy Dorper ewes between 2 and 5 years old were submitted to an estrous synchronisation protocol following the methodology described by Santarosa et al. (2019a). Laparoscopic fixed-time artificial insemination (FTAI) was performed with frozen semen (D0) of the same breed. A portable ultrasound machine (My LabTM30 Vet Gold Esaote®, Esaote Healthcare Brazil, São Paulo, Brazil) was used to diagnose pregnancy with a $5.0 \mathrm{MHz}$ frequency linear transducer during the transrectal examination (Jones \& Reed, 2017) at 30 days after FTAl and a second sampling was collected (D30).

Based on the number of foetuses observed at the pregnancy diagnosis performed on D30, the ewes were divided into two experimental groups: Group $1(\mathrm{G} 1)$, single pregnancy $(n=30)$ and Group 2 (G2), twin pregnancy $(n=30)$. The ewes in $G 1$ were $2.30 \pm 0.29$ years old and in $G 2$ the ewes were $2.38 \pm 0.32$ years old $(P=0.8554)$. For the number of deliveries, both groups were homogeneous (G1: $2.21 \pm 0.29$ deliveries; G2: $2.27 \pm 0.30$ deliveries; $P=0.8743$ ) and were composed of $40 \%$ of animals undergoing their first pregnancy, 30\% primiparous sheep (second pregnancy), and 30\% multiparous sheep (third or more pregnancies). The individual pregnancy status was considered a treatment; therefore, the non-pregnant 
animals were excluded from the study. For the next sampling time points, a $3.5 \mathrm{MHz}$ convex transducer was used to assess the foetal viability (Jones and Reed 2017).

The animals had access to a Vaquero grass (Cynodon dactylon) pasture, with bromatological analysis: $26.19 \%$ of dry matter (DM), $13.48 \%$ of crude protein (CP), $5.94 \%$ of ether extract (EE), $6.59 \%$ of mineral mixture (MM), $76.39 \%$ of neutral detergent fiber (NDF), and $33.75 \%$ of acid detergent fiber (ADF), during the day (from 7:00 am to 5:00 pm). In the late afternoon (5:00 pm), for security reasons, all animals were housed in collective and covered pens ( $2 \mathrm{~m}^{2} /$ animal) with rice straw beds, maintaining the hierarchy and treatment groups. After 5:00 pm, the pregnant ewes received, ad libitum, a maintenance feed (88\% DM, $20.85 \% \mathrm{CB}, 9.10 \% \mathrm{EE}, 6.27 \% \mathrm{MM}, 14.58 \% \mathrm{NDF}$, and $5.05 \% \mathrm{ADF})$ and corn silage (27.83\% DM, 8.28\% CP, $3.20 \% \mathrm{EE}, 3.84 \% \mathrm{MM}, 50.55 \% \mathrm{NDF}$, and $29.51 \% \mathrm{ADF}$ ) based on the maintenance nutritional requirements for pregnant sheep with single and twin pregnancies (NRC, 2007). Water and mineral salt (Ovinophos with Monensina ${ }^{\circledR}$, Tortuga Agrarian Zootechnical Company, Mairinque, São Paulo, Brazil) were available ad libitum in automatic troughs. Mineral analysis of the total diet (feed, corn silage, and pasture) was undertaken following the methodology described by Santarosa et al. (2019a), as well as the sanitary management. At the end of the experimental period, the ewes remained on the farm for lactation with their lambs.

\section{Data and sample collection}

Nine experimental sample times were defined: immediately after FTAI (D0); at $30 \mathrm{~d}$ (D30), $90 \mathrm{~d}$ (D90), 120 $\mathrm{d}$ (D120), $130 \mathrm{~d}$ (D130), and $140 \mathrm{~d}$ (D140) of pregnancy; immediately after delivery (DD); and at $24 \mathrm{~h}$ (PD1) and $48 \mathrm{~h}$ (PD2) postpartum.

Blood samples were taken from the external jugular vein using $30 \times 0.8 \mathrm{~mm}$ needles (BD Vacutainer ${ }^{\circledR}, \mathrm{BD}$ Medical, Curitiba, Paraná, Brazil) at 7:00 am at each experimental time point until D140 from the G1 and G2 groups. After delivery, blood samples were taken at a specific time for each ewe, i.e. at DD, PD1, and PD2. The animals were weighed, and the body condition score (BCS) (Russel 1991) was calculated after blood collection, from D0 to DD, before the lambs were delivered. The 60 ewes had a BCS of 2.5 to 4 at $\mathrm{DO}$ and at the final third pregnancy stage they had a BCS of 3 to 4 .

Coagulant activating gel vacuum tubes without anticoagulants were used. After coagulant retraction, the samples were centrifuged to obtain serum at 2,000 $\times \mathrm{g}$ for $10 \mathrm{~min}$ (Combate Celm ${ }^{\circledR}$ Centrifuge, Cia. Modern Laboratory Equipment, Barueri, São Paulo, Brazil). Aliquots of $2.0 \mathrm{~mL}$ of serum were separated into plastic tubes (Eppendorf $\circledast$, São Paulo-SP, Brazil) and stored at $-80^{\circ} \mathrm{C}$.

Measurements of glucagon (Sigma-Aldrich ${ }^{\circledR}$, Glucagon EIA kit, RAB0202, Merck KGaA, Darmstadt, Germany), cortisol (DRG® Cortisol enzyme-linked immunosorbent assay (ELISA) EIA-1887, @DRG Instruments, Deutschland), insulin (DRG® ELISA EIA-2935, @ DRG Instruments), thyroid T3 (DRG® ELISA EIA-1780, @DRG Instruments), and T4 (DRG® ELISA EIA-4568, @DRG Instruments) were taken using a commercial ELISA kit in a microplate reading spectrophotometer (Biotek ${ }^{\circledR}$ Power Wave XS, BioTek 
Instruments, Inc., Winooski, VT, USA) at the Laboratory of Experimental Research on Gynecology and Obstetrics, Botucatu Medical School, São Paulo State University, Botucatu Campus.

The CHEM8 + cartridge (I-STAT ${ }^{8}$, Abbott Laboratories, Illinois, USA) was used to measure the blood glucose, besides other blood gas parameters (Santarosa et al. 2019b). A $1 \mathrm{~mL}$ blood sample was taken by jugular vein puncture with a polyethylene syringe containing sodium heparin (Hemofol ${ }^{\circledR} 5.000 \mathrm{IU} / \mathrm{mL}$, Cristália Prod. Quim. Farm. Ltda, São Paulo, Brazil) using a $30 \times 0.8 \mathrm{~mm}$ needle (BD ${ }^{\circ}, \mathrm{BD}$ Medical). Immediately after, blood gas analysis was performed on a portable $\mathrm{pH}$, electrolyte, and blood gas analyser (I-STAT®, Abbott Laboratories).

The HOMA IR was calculated according to the following formula: fasting insulin $(\mu \mathrm{UI} / \mathrm{mL}) \times$ fasting glucose (mmol/L)/22.5 (Matthews et al. 1985). To convert glucose from $\mathrm{mg} / \mathrm{dL}$ to $\mathrm{mmol} / \mathrm{L}$, the value in $\mathrm{mg} / \mathrm{dL}$ was multiplied by 0.0555 (Oliveira et al. 2005).

\section{Statistical analysis}

For all variables analysed, the animal was considered the experimental unit. All data were analysed using the PROC MIXED procedure of SAS (Version 9.4; SAS Inst. Inc.; Cary, NC) and the Kenward-Roger approximation was calculated to determine the denominator $\mathrm{df}$ for the test of fixed effects. For the analysis, the model statement contained the effect of groups (G1 and G2), sample time, and groups by sample time interaction. Data were analysed using the animal as the random variable, whereas the specified term for the repeated statement was the sample time and the subject was the animal (groups). The covariance structure used was heterogeneous autoregressive, which provided the best fit for these analyses considering the smallest Akaike Information Criterion Corrected. The results were reported as the least square means and for all data significance was set at $P \leq 0.05$. Pearson's correlations were calculated between all parameters $(P \leq 0.05)$, including all sample times and both groups $(\mathrm{n}=60 \times 9$ sample times, totalling 540 samples).

Table 1. Pearson correlation of blood glucose $(\mathrm{mg} / \mathrm{dL})$, insulin $(\mathrm{ng} / \mathrm{mL})$, cortisol $(\mathrm{ng} / \mathrm{mL})$ and HOMA IR of Dorper ewes from both from both single (G1) and twin pregnancy (G2) at nine experimental sample times $(n=540)$. 


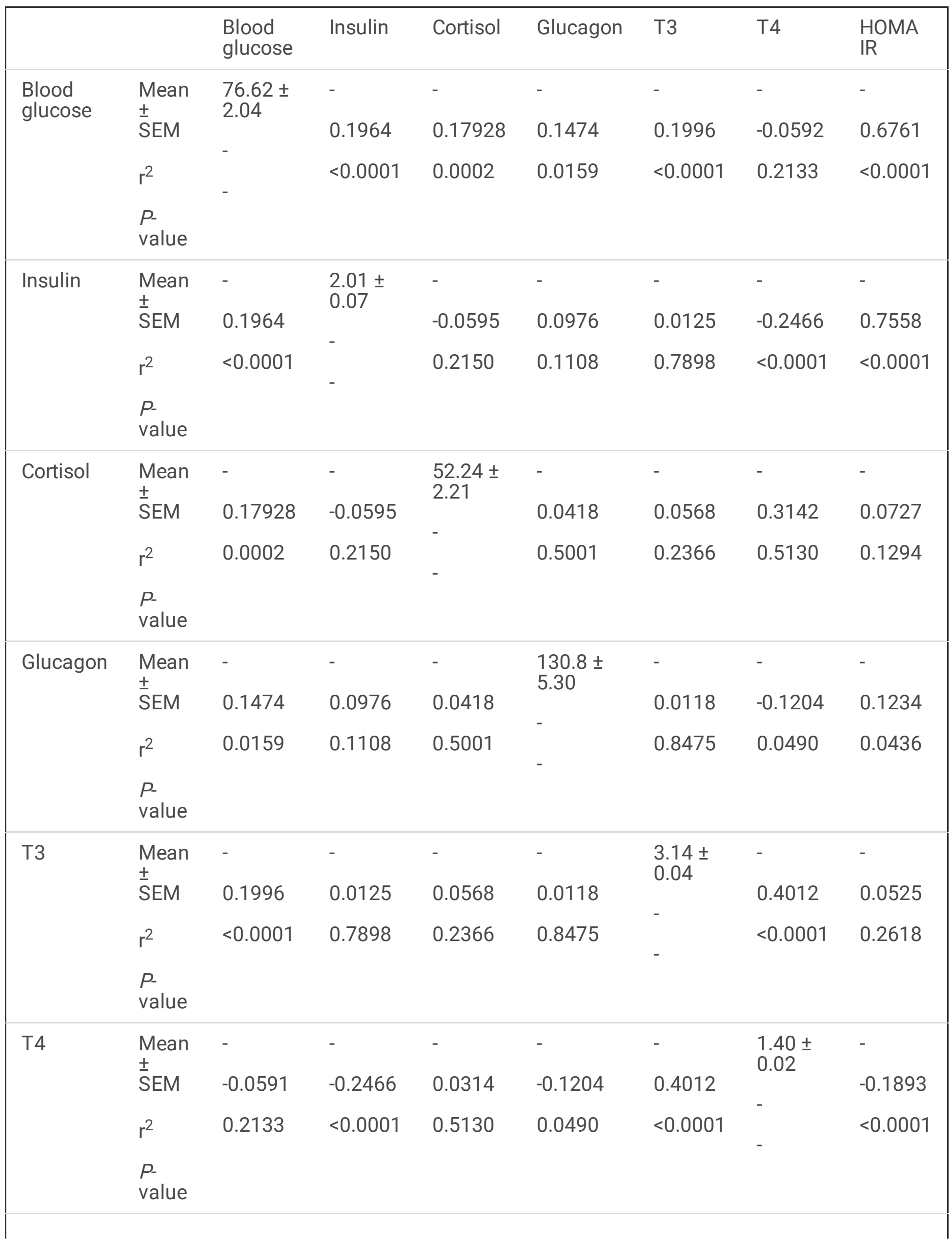




\begin{tabular}{|c|c|c|c|c|c|c|c|c|}
\hline \multirow[t]{2}{*}{ HOMA IR } & $\begin{array}{l}\text { Mean } \\
\pm \\
\text { SEM }\end{array}$ & $\begin{array}{l}- \\
0.6760\end{array}$ & $\begin{array}{l}- \\
0.7558\end{array}$ & $\begin{array}{l}- \\
0.0727\end{array}$ & $\begin{array}{l}- \\
0.1234\end{array}$ & $\begin{array}{l}- \\
0.0525\end{array}$ & $\begin{array}{l}- \\
-0.1893\end{array}$ & $\begin{array}{l}10.63 \pm \\
12.54\end{array}$ \\
\hline & $r^{2}$ & $<0.0001$ & $<0.0001$ & 0.1294 & 0.0436 & 0.2618 & $<0.0001$ & \\
\hline
\end{tabular}

Data presented as means \pm standard deviations $(\mathrm{sd})$, correlation coefficient $\left(\mathrm{r}^{2}\right)$.

\section{Results}

The body weight (BW) means of the G1 group were $45.6 \pm 6.5 \mathrm{~kg}$ at D0, $67.6 \pm 8 \mathrm{~kg}$ at D140, and $61.7 \pm$ 8.5 at DD, and the means of the $\mathrm{G} 2$ group were $54.1 \pm 7.7 \mathrm{~kg}$ at D0, $76.4 \pm 7.8 \mathrm{~kg}$ at D140, and $68.3 \pm 8.6$ immediately after delivery (Figure 1). The $\mathrm{G} 2$ group showed a higher BW mean than the $\mathrm{G} 1$ group $(\mathrm{P}=$ $0.0001)$ due to twin gestation; however, this difference was observed from $D 0$. There was also a time effect for BW as the gestation progressed $(P<0.0001)$, with the highest value observed at $D 140$. In DD, significant weight loss was noted due to parturition.

Blood glucose, insulin, cortisol, T3, T4, and HOMA IR showed significant differences over time $(P<$ $0.0001)$, as well as for glucagon $(P=0.02)$. However, there was a difference only for cortisol $(P=0.04)$ between the groups. The interaction of the groups in the nine sample times revealed a significant result $(P=0.001)$ only for glucagon.

The blood glucose means (Figure 2) were equal in the two groups $(P=0.06)$. However, in both groups the glucose was higher at the D0 and DD time points $(P<0.0001)$. The insulin concentrations (Figure 3$)$ were increased $(P<0.0001)$ for both groups at DD, with the highest value for the $\mathrm{G} 1$ group at PD2 and the G2 group at PD1.

Glucagon levels (Figure 4) showed interaction within groups and sample times $(P=0.001)$ and were different among sample times $(P=0.02)$. Between groups, the glucagon means were different at $\mathrm{D} 0(P=$ $0.02)$ and $\mathrm{D} 130(P=0.02)$, with the $\mathrm{G} 1$ group having higher values than the $\mathrm{G} 2$ group. At $\mathrm{D} 140$, the $\mathrm{G} 2$ group showed a higher glucagon mean than the $\mathrm{G} 1$ group $(P=0.0006)$.

The thyroid hormones, T3 (Figure 5) and T4 (Figure 6), showed different behaviours among the various time points $(P<0.0001)$. The highest T3 and T4 values were at D0 and the lowest were at D90 for both groups. There was a decrease from D0 to D90, whereas from D120 to DP2 the values remained in a similar range for both groups.

The means of cortisol concentration (Figure 7) were different between the two groups $(P=0.0434)$, as shown by the higher values in the $\mathrm{G} 1$ group than in the $\mathrm{G} 2$ group at all sample times. The highest means were at DD and the lowest were at PD2 in both groups $(P<0.0001)$. 
The HOMA IR values (Figure 8) were different among the time points $(P<0.0001)$; however, they did not differ between groups $(P=0.98)$. The highest means were found at DD, followed by PD1 and PD2, which was similar to the results found for blood glucose values.

Based on Pearson's correlation (Table 1), there were positive correlations between glucose $\times$ insulin $(P<$ $0.0001)$, glucose $\times$ cortisol $(P=0.0002)$, glucose $\times$ glucagon $(P=0.0159)$, glucose $\times$ T3 $(P<0.0001)$, glucagon $\times$ HOMA IR $(P=0.0436)$, and T3 $\times$ T4 $(P<0.0001)$. The correlations were negative between insulin $\times \mathrm{T} 4(P<0.0001)$, glucagon $\times \mathrm{T} 4(P=0.049)$, and HOMA IR $\times \mathrm{T} 4(P<0.0001)$.

\section{Discussion}

The higher BW mean found in the $\mathrm{G} 2$ group compared to the $\mathrm{G} 1$ group from D0 can be justified by higher ovulation and prolificacy rates in the G2 group compared to the G1 group (Santarosa et al. 2019a).

The highest blood glucose level (Figure 2) was at DD for both groups; however, no differences were observed between groups at PD1 and PD2. In both groups, the animals were hyperglycemic (Kaneko et al. 2008) at D0 and DD. The hyperglycemia observed in D0, even for the ewes who were not pregnant, was due to the stress caused by handling during the insemination procedures and heat synchronisation.

A significant positive correlation $(r 2=0.179 ; P=0.0002$, Table 1$)$ was obtained between blood glucose and cortisol levels, which might explain the stress of ewes at D0 and DD, when cortisol levels were higher, and as a trigger effect of foetal expulsion. A previous study also observed a moderate correlation between blood glucose and cortisol levels $(r 2=0.338 ; P=0.001)$ in ewes during delivery (Araújo et al. 2014) and noticed that blood glucose increased at birth for pregnant ewes regardless of the foetus number. In this study, during pregnancy blood glucose values remained within the normal range for the species, which corroborated with the findings from the present study. The increased glucose concentration during parturition suggests higher glucagon and glucocorticoid concentrations that promote the depletion of hepatic glycogen stores and energy mobilisation because of glucocorticoid release at delivery in sheep (Santos et al. 2011; Araújo et al. 2014). These findings support those of the present study, where a positive correlation was detected between blood glucose and cortisol levels.

Insulin is an important hormone of energy metabolism and promotes extracellular to intracellular glucose uptake, thus being stored as glycogen and as a substrate for lipogenesis. Insulin values (Figure 3) increased throughout pregnancy in single and twin gestations, especially at DD, which has been verified by other authors (Araújo et al., 2014) who observed an increase at lambing compared to previous gestational periods.

The glucagon values were the only parameter that showed an interaction of groups by sample time points (Figure 4); therefore, the number of lambs and gestational stage altered the levels of this hormone. Glucagon participates in homeostatic functions with hepatic glucose mobilisation when animals are hypoglycaemic (Jiang and Zhang 2003) and during lipid metabolism (Vernon et al. 2005; Oikawa and Oetzel 2006; Zhang et al. 2011). Glucagon is not as useful in the hyperglycemic effect as glucocorticoids 
during stressful situations (Jiang and Zhang 2003), such as delivery. However, the G1 group had the highest glucagon level at DD, whereas for the $\mathrm{G} 2$ group the highest levels was at D140 before lambing (Figure 4).

Adhikari et al. (2018) found a suppression of glucagon secretion when animals were exposed to high energy diets. In the present experiment, the animals were maintained under the same nutritional diet; however, during pregnancy there was fatty acids mobilisation, with changes in cholesterol and triglycerides levels (Santarosa et al., 2019a), that can generate a negative feedback of glucagon secretion. Glucagon concentration showed large oscillations among sample time points and between groups analysed in the present study, although it did not represent a metabolic change due to pregnancy. Other authors have found no differences in glucagon concentrations among ewes with one, two, or three foetuses, or among pregnant and non-pregnant animals, probably due to pregnant ewes being in healthy condition (Araújo et al. 2014).

The increase of the glycolytic pathway inhibits glycolysis and gluconeogenesis, reducing hepatic glucose production and the formation of ketone bodies (Frise et al. 2013). In dairy cows, insulin concentration decreases at the late gestation and early lactation stages, with acute peaks at calving (Vernon et al. 2005; Oikawa and Oetzel 2006). In goats, lower insulin levels were observed in PT (Hefnawy et al. 2011; Souto et al. 2013), which was also shown by Henze et al. (2008), Santos et al. (2011), Duehlmeier et al. (2013), and Souto et al. (2019) in sheep. This condition was justified by Schmitt et al. (2012), who reported higher peripheral tissue resistance to insulin in sheep during the third gestation stage. During this period, peripheral tissues have lower glucose metabolising capacity and, as the pregnancy progresses, maternal insulin concentration and insulin response to glucose overload are decreased (Sivan and Boden 2003; Duehlmeier et al. 2013). Lower insulin concentration is influenced by NEFA increase (Regnault et al. 2004), as evidenced by the strong negative relationship that causes IR in peripheral tissues and reduces insulin production, even though it provides a source of energy for maternal metabolism (Duehlmeier et al. 2013). Glucose is then available for placental use and to meet foetal demand. Further studies need to be undertaken to evidence this relationship. Nevertheless, there might only be limited evidence of these interactions among gestational hormones and the maternal pancreas because of the chronic elevation of NEFA due to NEB (Souto et al. 2013; Kalyesubula et al. 2019).

The thyroid hormone profiles (T3, Figure 5 and T4, Figure 6) were similar, with an increase during the second half of pregnancy, from D90 to D140, when the ewes had to increase their metabolic rate due to delivery (Araújo et al., 2014). This increase of thyroid concentration in pregnant ewes is related to their important role in energy metabolism (Kalyesubula et al. 2020). In non-pregnant animals, these hormones are indicators of the metabolic and nutritional status of the herd. Energy deprivation causes a decrease in T3 levels and the energy excess has the opposite effect (Todini et al. 2007). In pregnant ewes, the higher thyroid activity is due to the increase of binding protein concentration, placental secretion of thyrotrophic factors, and pituitary response of the thyroid stimulating hormone, which induces the release of thyrotropic hormone by the hypothalamus (Celi et al. 2008). 
The increase of T3 and T4 concentrations during the final third of pregnancy in both groups in the present study agreed with the observations made by Araújo et al. (2014) in Santa Inês sheep and Todini et al. (2007) in goats. Therefore, as gestation progress, the metabolic rate increases. However, these results contradicted other authors, that found a reduction in T4 concentration during pregnancy until delivery (Yildiz et al. 2005). They attributed this decrease to the NEB at final pregnancy and observed lower levels of thyroid hormone concentration in pregnant females with twin gestation, especially during the final gestation due to NEB being more pronounced compared to the single gestation (Yildiz et al. 2005). Positive moderate correlation between T3 $\times$ T4 $(r 2=0.4012 ; P<0.0001)$, taking into consideration that T3 is derived from T4. However, homeostasis under glucose metabolism influenced the T4 excretion, which was observed in the weak negative correlations found between T4 $\times$ insulin $(r 2=-0.2466 ; P<$ $0.0001), T 4 \times$ glucagon $(r 2=-0.1204 ; P<0.0490)$, and T4 $\times$ HOMA IR $(r 2=-0.1893 ; P<0.0001)$.

Although the $\mathrm{G} 1$ group showed higher cortisol levels than the $G 2$ group $(P=0.0434$; Figure 7), it remained under the normal range ( $<80 \mathrm{ng} / \mathrm{mL}$ ) for sheep (Caroprese et al. 2010) and did not interfere with glucose concentration. In both groups, the cortisol means increased at DD and decreased at PD2, which was in agreeance with previous studies (Kalyesubula et al., 2020). Stress situations may cause the elevation in the level of this glucocorticoid (Ford et al. 1990), justifying the high values at D0 when the ewes were under reproduction management. This hormone plays an important role in peripartum due to its potent gluconeogenic effect; however, its concentration progressively decreases at the postpartum period compared to the last weeks of gestation (Bani Ismail et al. 2008; Campos et al. 2010), corroborating the findings of the present study.

Hefnawy et al. (2011) and Souto et al. (2013) reported a significant increase in cortisol levels in goats with PT, as did Ford et al. (1990) in sheep. These results can be explained by the increase in adrenal production, or the inability to metabolise and excrete circulating cortisol in the fatty liver occurring in PT. In contrast, Bani Ismail et al. (2008) found no significant difference between the cortisol levels in healthy goats and subclinical PT. Thus, cortisol effectively acts in the opposite way of insulin, allowing tissues to use glucose even at low blood concentrations (Souto et al. 2013). This inhibitory effect on glucose utilisation might be increased under conditions of severe insulin deficiency and the severity of ketosis, as shown by the balance between cortisol and insulin levels rather than the absolute amount of each secreted hormone (Campos et al., 2010). Thus, the degree of inhibition of glucose utilisation and the clinical signs might depend on the balance of cortisol and insulin levels (Firat and Özpinar 2002). In the present study, the correlation between cortisol and insulin was negative (Table 1), but it was not significant $(r 2=-0.0595 ; P=0.21)$.

The HOMA IR (Figure 8) values were very similar between the two groups $(P=0.98)$; therefore, the number of foetuses did not influence this parameter, which represents IR (Vasques et al. 2008). The means of both groups increased at DD compared to previous sample time points; therefore, ewes had greater IR during the peripartum period. The highest index was found at DD in the G1 (32.94 \pm 3.87$)$ and G2 (31.05 \pm 4.45 ) groups efficiently denoted the IR of ewes, although other studies with sheep did not find such high HOMA IR values (Duckett et al. 2014; Kalyesubula et al. 2020). Lambs that received high- and low-calorie 
diets showed values of HOMA IR of 7.3 and 3.1, respectively, and the authors concluded that the highcalorie diet caused greater IR, hyperglycemia, and hyperinsulinemia than the low-calorie diet (Kalyesubula et al. 2020). Another study with lambs found values from 1.5 to 3.5 (Duckett et al., 2014).

In humans, normal average values for HOMA IR are up to 2.8 (Matthews et al. 1985; Oliveira et al. 2005). However, in non-pregnant ewes (D0), the mean values were around 5.5. At D90, the ewes displayed the lowest values, which were more similar to humans and other studies with sheep (Kalyesubula et al. 2020). At the beginning of the experiment, the higher means could be justified by positive and high correlation with blood glucose levels $(r 2=0.6760 ; P<0.0001)$. There was no significant positive correlation between HOMA IR and cortisol levels ( $r 2=0.1294$; $\mathrm{P}=0.0727)$; however, this analysis included both groups and all sample time points $(n=540)$. The D0 values were higher than D90 probably due to the increased cortisol levels at this specific time point because of FTAl management. These factors could increase blood glucose levels and the HOMA IR.

Decreased insulin sensitivity is observed at different life stages and is physiological at puberty, ageing, and pregnancy (Duehlmeier et al. 2013; Brondani et al. 2016; Sadegzadeh-Sadat et al. 2021). A complex endocrine-metabolic adaptation occurs during pregnancy involving changes in insulin sensitivity, increased $\beta$ cell mass response, slight elevation of blood glucose after feeding (Duehlmeier et al. 2013), and changes in circulating levels of phospholipids, free fatty acids, triglycerides, and cholesterol (Santarosa et al. 2019a). These changes are physiological because they represent a metabolic adaptation of the adequate energy supply to the foetus and preparation of the mother for delivery and lactation. The foetus cannot perform gluconeogenesis and its growth depends on the placental supply of maternal nutrients. The IR of pregnant females decreases the glucose utilisation, which is redirected to foetal tissue development (Oliveira et al. 2005). Although there is limited information regarding the use of this index in small ruminants (Duehlmeier et al. 2013; Duckett et al. 2014; Kalyesubula et al. 2020), it can be a valuable tool to understand sheep metabolism. Therefore, further studies should be undertaken to evaluate the applicability of the HOMA $\beta$ index to understand the profile in ewes, and thus establish standard references.

In conclusion, the number of foetuses in the gestation of ewes directly interferes with the glucagon profile throughout gestation and insulin concentration postpartum. Other endocrine-metabolic adaptations were observed owing to delivery, such as increases in cortisol, and T3 and T4 hormone levels, related to the physiological hyperglycemic effects contributing to the resolution of postpartum physiological stress. Higher IR was suggested with the proximity of delivery, which was shown in the HOMA IR values. The importance of good nutritional management from conception until the postpartum period was emphasised by monitoring different animal parameters and evaluating the metabolic and hormonal profiles to avoid PT and consequent economic losses.

\section{Declarations}

\section{Author contribution}


B.P. Santarosa: Data curation, Formal analysis, Investigation, Methodology, Writing - original draft. D.O.L. Ferreira: Conceptualization, Investigation, Methodology. H.B. Hooper: Translation, Writing - review \& editing. Y.K. Sinzato: Formal analysis, Investigation, Methodology. D.C. Damasceno: Data curation, Formal analysis, Investigation, Methodology. D.M. Polizel: Statistical analysis. E.G. Fioratti: Writing review \& editing. V.H. Santos: Data curation, Formal analysis, Investigation, Methodology. A.A. da Silva: Visualization, Supervision, Writing - review \& editing. R.C. Gonçalves: Funding acquisition, Visualization, Supervision. All the authors read and approved the final manuscript.

\section{Funding}

The authors thank the São Paulo State Research Support Foundation (FAPESP) for the regular grant to the research project [Process 2015/08714-8] for their financial support in covering all the laboratory costs, including commercial ELISA kits, cartridge for portable blood gas analyzer (blood glucose) and others consumables; the Coordination of Improvement of Personal Higher Education (CAPES) for the PhD Scholarship granted, that guaranteed the exclusivity and financial support for doctoral student (Santarosa, B.P.) to execute the project.

\section{Availability of data and material}

The authors assure that the data and materials support the published claims and comply with field standards. The datasets analyzed during the current study are available from the corresponding author on reasonable request.

\section{Code availability}

Data were analyzed using SAS (9.4).

\section{Acknowledgements}

The authors thank the School of Veterinary Medicine and Animal Science of São Paulo State University (FMVZ/UNESP) and the Laboratory of Experimental Research on Gynecology and Obstetrics, Botucatu Medical School, São Paulo State University (FMB/UNESP), Botucatu, São Paulo State, for the infrastructure and equipment used to conduct the experiment; the Araí \& Zumbi farm, Pardinho, São Paulo State, for the use of the animals and for assistance with sample collection.

\section{Ethics approval}

All the procedures used in this study have been approved by the Animal Use Ethics Committee of the School of Veterinary Medicine and Animal Science, São Paulo State University, Botucatu Campus (Protocol No. 189/2014).

\section{Consent for publication}


This study has been approved by the Animal Use Ethics Committee of the School of Veterinary Medicine and Animal Science, São Paulo State University, Botucatu Campus.

\section{Conflict of interest}

The authors declare no competing interests.

\section{References}

Adhikari B., Khanal P., Nielsen M.O., 2018. Impacts of pre and postnatal nutrition on glucagon regulation and hepatic signaling in sheep. Journal of Endocrinology, 238(1): 1-12. doi: 10.1530/JOE-17-0705

Araújo C.A.S.C., Nikolaus J.P., Morgado A.A., Monteiro B.M., Rodrigues F.A.M.L., Vechiato T.A.F., Soares P.C., Sucupira M.C.A., 2014. Energetic and hormonal profile of Santa Ines ewes in the middle of gestation to postpartum. Pesquisa Veterinária Brasileira, 34(12): 1249-1255. doi:10.1590/S0100736X2014001200019

Bani Ismail Z., Al-Majali A.M., Amireh F., Al-Rawashdeh O.F., 2008. Metabolic profiles in goat does in late pregnancy with and without subclinical pregnancy toxaemia. Veterinary Clinical Pathology, 37(4): 434437. doi: 10.1111/j.1939-165X.2008.00076.x

Brondani W.C., Lemes J.S., Ferreira O.G.L., Roll V.F.B., Del Pino F.A.B., 2016. Metabolic profile in pregnant sheep. Archivos de Zootecnia, 65: 1-6.

Caldeira R.M., Belo A.T., Santos C.C., Vazques M.I., Portugal A.V., 2007. The effect of body condition score on blood metabolites and hormonal profiles in ewes. Small Ruminant Research, 68(3): 233-241. doi:

10.1016/j.smallrumres.2005.08.027

Campos A.G., Afonso J.A.B., Santos R.A., Mendonça C.L., Guimarães J.A., 2010. Clinical and laboratorial study of Pregnancy toxaemia in ewes: Retrospective analysis. Ciência Animal Brasileira, 11(3): 623-628. doi: 10.5216/cab.v11i3.5499

Caroprese M., Albenzio M., Marzano A., Schena L., Annicchiarico G., Sevi A., 2010. Relationship between cortisol response to stress and behavior, immune profile, and production performance of dairy ewes. Journal of Dairy Science, 93(6): 2395-2403. doi: 10.3168/jds.2009-2604

Celi P., Di Trana A. \& Claps S. (2008). Effects of perinatal nutrition on lactational performance, metabolic and hormonal profiles of dairy goats and respective kids. Small Ruminant Research, 79(2-3): 129-136. doi: 10.1016/j.smallrumres.2008.07.010

Duckett S.K., Volpi-Lagreca G., Alende M., Long N.M., 2014. Palmitoleic acid reduces intramuscular lipid and restores insulin sensitivity in obese sheep. Diabetes, Metabolic Syndrome and Obesity: Targets and Therapy, 7: 553-563. doi: 10.2147/DMSO.S72695 
Duehlmeier R., Fluegge I., Schwert B., Ganter M., 2013. Insulin Sensitivity during Late Gestation in Ewes Affected by Pregnancy Toxemia and in Ewes with High and Low Susceptibility to this Disorder. Journal of Veterinary Internal Medicine, 27(2): 359-366. doi: 10.1111/jvim.12035

Firat A., Özpinar A., 2002. Metabolic Profile of Pre-Pregnancy, Pregnancy and Early Lactation in Multiple Lambing Sakiz Ewes 1. Changes in plasma glucose, 3-hydroxybutyrate and Cortisol Levels. Annals of Nutrition and Metabolism, 46(2): 57-61. doi: 10.1159/000057641

Ford E.J., Evans J., Robinson I., 1990. Cortisol in pregnancy toxemia of sheep. British Veterinary Journal, 146(6): 539-542. doi: 10.1016/0007-1935(90)90057-A

Frise C.J., Mackillop L., Joash K., Williamson C., 2013. Starvation ketoacidosis in pregnancy. European Journal of Obstetrics \& Gynecology and Reproductive Biology, 167(1): 1-7.

doi: 10.1016/j.ejogrb.2012.10.005

Hefnawy A.E., Shousha S., Youssef S., 2011. Hematobiochemical profile of pregnant and experimentally pregnancy toxemic goats. Journal of Basic and Applied Chemistry, 1: 65-69.

Henze P., Bickhardt K., Fuhrmann H., Sallmann H.P., 1998. Spontaneous pregnancy toxaemia (Ketosis) in sheep and the role of insulin. Zentralbl Veterinarmed A, 45(5), 225-226. doi: 10.1111/j.1439-

0442.1998.tb00825.x

Husted S.M., Nielsen M.O., Blache D., Ingvartsen K.L., 2008. Glucose homeostasis and metabolic adaptation in the pregnant and lactating sheep are affected by the level of nutrition previously provided during her late fetal life. Domestic Animal Endocrinology, 34: 419-431.

doi: 10.1016/j.domaniend.2007.12.002

Jiang G., Zhang B.B., 2003. Glucagon and regulation of glucose metabolism. American Journal of Physiology-Endocrinology and Metabolism, 284: 671-678. doi:10.1152/ajpendo.00492.2002

Jones A.K., Reed S.A., 2017. Benefits of ultrasound scanning during gestation in the small ruminant. Small Ruminant Research, 149: 163-171. doi: 10.1016/j.smallrumres.2017.02.008

Kalyesubula M., Mopuri R., Rosov A., Alon T., Edery N., Moallem U., Dvir H., 2020.

Hyperglycemia-stimulating diet induces liver steatosis in sheep. Scientific Reports. Nature Research. 10:12189. doi: 10.1038/s41598-020-68909-z

Kalyesubula M., Rosov A., Alon T., Moallem U., Dvir H., 2019. Intravenous infusions of glycerol versus propylene glycol for the regulation of negative energy balance in sheep: A randomized trial. Animals. 9(10): 731. doi: 10.3390/ani9100731

Kaneko J.J., Harvey J.W., Bruss M.L., 2008. Clinical biochemistry of domestic animals. 6.ed. San Diego: Academic. 916p. 
Matthews D., Hosker J.P., Rudenski A.S., Naylor B.A., Treacher D.F., Turner R.C., 1985. Homeostasis model assessment: insulin resistance and $\beta$-cell function from fasting glucose and insulin concentrations in man. Diabetologia. 28: 412-419. doi: 10.1007/BF00280883

NRC, 2007. Nutrient Requirements of Small Ruminants: sheep, goats, cervids and New World camelids. Natl Acad. Press, Washington, DC. 384p.

Oikawa S., Oetzel G.R., 2006. Decreased insulin response in dairy cows following a four-day fast to induce hepatic lipidosis. Journal of Dairy Science, 89: 2999- 3005. doi: 10.3168/jds.S00220302(06)72572-3

Oliveira E.P., Souza M.L.A., Lima M.D.A., 2005. HOMA (homeostasis model assessment) index in clinical practice: a review. Jornal Brasileiro de Patologia e Medicina Laboratorial, 41(4): 237-243. doi: 10.1590/S1676-24442005000400004

Regnault T.R.H., Oddy H.V., Nancarrow C., Sriskandarajad N., Scaramuzzi R.J., 2004. Glucose-stimulated insulin response in pregnant sheep following acute suppression of plasma non-esterified fatty acid concentrations. Reproductive Biology and Endocrinology, 2: 1-10. doi: 10.1186/1477-7827-2-64

Russel A., 1991. Body condition scoring of sheep. In: E. Boden (Ed.) Sheep and Goat Practice. Bailliere Tindall, Philadelphia. p3.

Sadegzadeh-Sadat M., Anassori E., Khalilvandi-Behroozyar H., Asri-Rezaei S., 2021. The effects of ZincMethionine on glucose metabolism and insulin resistance during late pregnancy in ewes. Domestic Animal Endocrinology, 77: 106647. doi: 10.1016/j.domaniend.2021.106647.

Santarosa B.P., Dantas G.N., Ferreira D.O.L., Santos B., Takahira R.K., Carvalho M.G., Silva A.A., Gonçalves R.C., 2019a. Comparison of biochemical parameters between single and twin pregnancies of Dorper breed ewes during gestation, lambing and postpartum. Arquivo Brasileiro de Medicina Veterinária e Zootecnia, 71(4): 1307-1315. doi: 10.1590/1678-4162-10699

Santarosa B.P., Dantas G.N., Ferreira D.O.L., Carvalho M.G., Rodrigues M., Pereira P.F.V., Silva A.A., Gonçalves R.C. 2019b. Comparison of electrolyte and acid-base balances of Dorper breed ewes between single and twin pregnancies. Pesquisa Veterinária Brasileira, 39(10): 789-795. doi: 10.1590/1678-5150PVB-5952

Santos F.C.O., Mendonça C.L., Silva Filho A.P., Carvalho C.C.D., Soares P.C., Afonso J.A.B., 2011. Biochemical and hormonal indicators of natural cases of pregnancy toxaemia of in sheep. Pesquisa Veterinária Brasileira, 31(11): 974-980. doi: 10.1590/S0100-736X2011001100006

Schlumbohm C., Harmeyer J., 2003. Hypocalcemia reduces endogenous glucose production in hyperketonemic sheep. Journal of Dairy Science, 86(6): 1953-1962. doi: 10.3168/jds.S00220302(03)73783-7 
Schmitt E., Schneider A., Gourlat M.A., Schwegler E., Pereira R.A., Hoffmann D.C.A., Lopes M.S., Hax L.T., Del Pino F.A.B., Corrêa M.N., 2012. Calcium and insulin correlation during the glucose tolerance test in pregnant and non-pregnant ewes. Arquivo Brasileiro de Medicina Veterinária e Zootecnia, 64(5): 11271132. doi: 10.1590/S0102-09352012000500006

Sivan E., Boden G., 2003. Free fatty acids, insulin resistance, and pregnancy. Current Diabetes Reports, 3: 319-322. doi:10.1007/s11892-003-0024-y

Souto R.C.J., Afonso J.A.B., Mendonça C.L., Carvalho C.C.D., Silva Filho A.P., Cajueiro J.F.P., Lima E.H.F., Soares P.C., 2013. Biochemical, electrolytic and hormonal findings in goats affected with pregnancy toxemia. Pesquisa Veterinária Brasileira, 33(10): 1174-1182. doi: 10.1590/S0100-736X2013001000002

Souto R.C.J., Afonso J.A.B., Mendonça C.L., Dantas A.F.M., Cajueiro J.F.P., Gonçalves D.N.A., Oliveira Filho E.F., Soares P.C., 2019. Biochemical, endocrine, and histopathological profile of liver and kidneys of sheep with pregnancy toxemia. Pesquisa Veterinária Brasileira, 39(10): 780-788. doi: 10.1590/1678-5150-PVB6400

Todini L., Malfatti A., Valbonesi A., Trabalza-marinucci M., Debenedetti A., 2007. Plasma total T3 and T4 concentrations in goats at different physiological stages, as affected by energy intake. Small Ruminant Research, 68(3): 285-290. doi: 10.1016/j.smallrumres.2005.11.018

Vasques A.C.J., Rosado L.E.F.P.L., Alfenas R.C.G., Geloneze B., 2008. Critical analysis on the use of the homeostasis model assessment (HOMA) indexes in the evaluation of the insulin resistance and the pancreatic beta cells functional capacity. Arquivo Brasileiro de Endocrinologia e Metabologia, 52(1): 3239. doi: 10.1590/S0004-27302008000100006

Vernon R.G., 2005. Lipid metabolism during lactation: A review of adipose tissue-liver interactions and the development of fatty liver. Journal of Dairy Science, 72(4): 460-469. doi: 10.1017/S0022029905001299

Yildiz A., Balikci E., Gurdogan F., 2005. Serum Mineral Levels at Pregnancy and Postpartum in Single and Twin Pregnant Sheep. Biological Trace Element Research, 107(3): 247-258. doi: 10.1385/BTER:107:3:247

Zhang L., Long N.M., Hein S.M., Ma Y., Nathanielsz P.W., Ford S.P., 2011. Maternal obesity in ewes results in reduced foetal pancreatic $\beta$-cell numbers in late gestation and decreased circulating insulin concentration at term. Domestic Animal Endocrinology, 40(1): 30-39.

doi: 10.1016/j.domaniend.2010.08.004

\section{Figures}




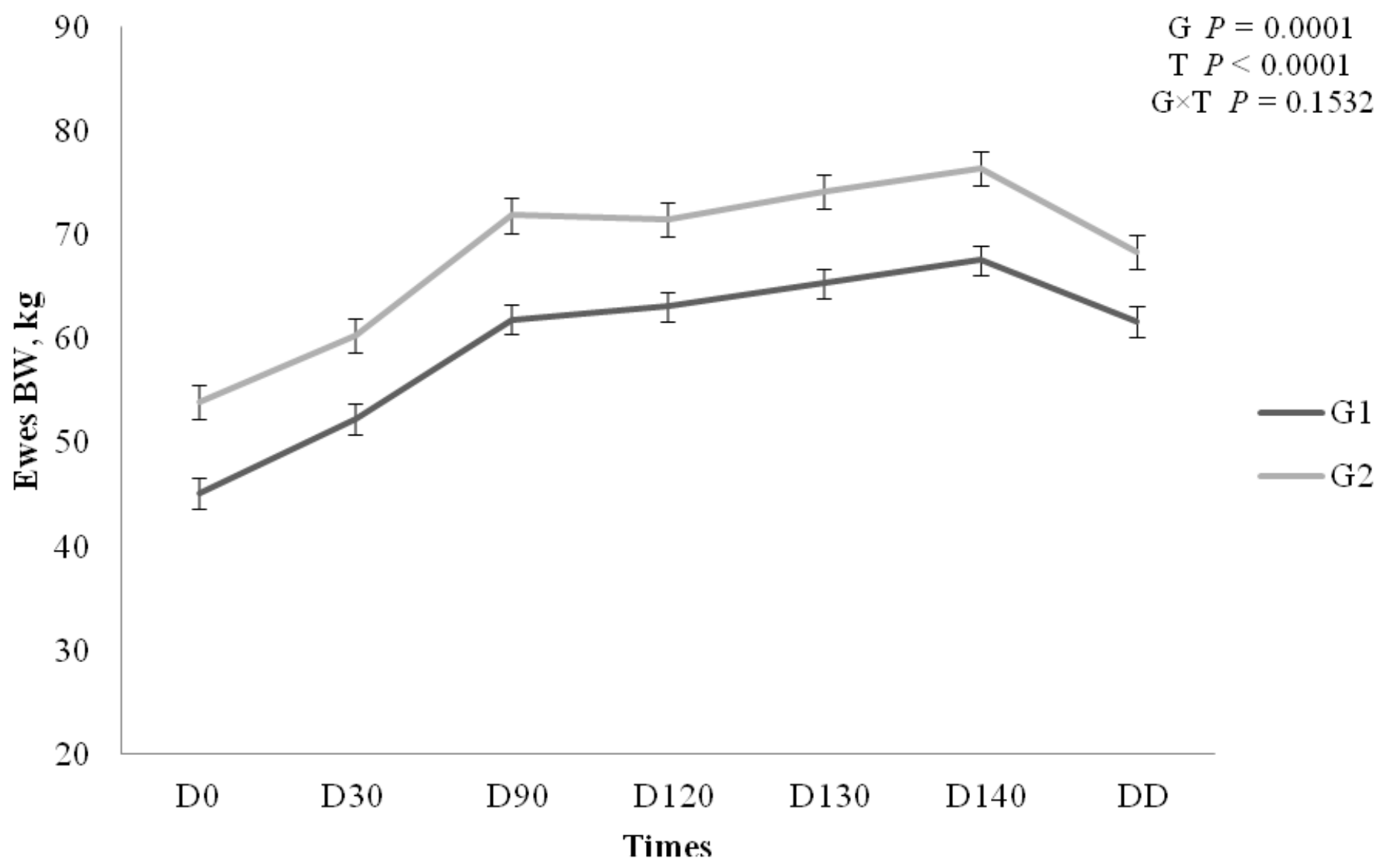

\section{Figure 1}

Body weight (BW, kg) of Dorper ewes from single (G1) and twin pregnancy (G2) at nine experimental sample times. Data presented as means \pm standard errors. $G=$ group effect; $T=$ time effect; $G \times T=$ group and time interaction. 


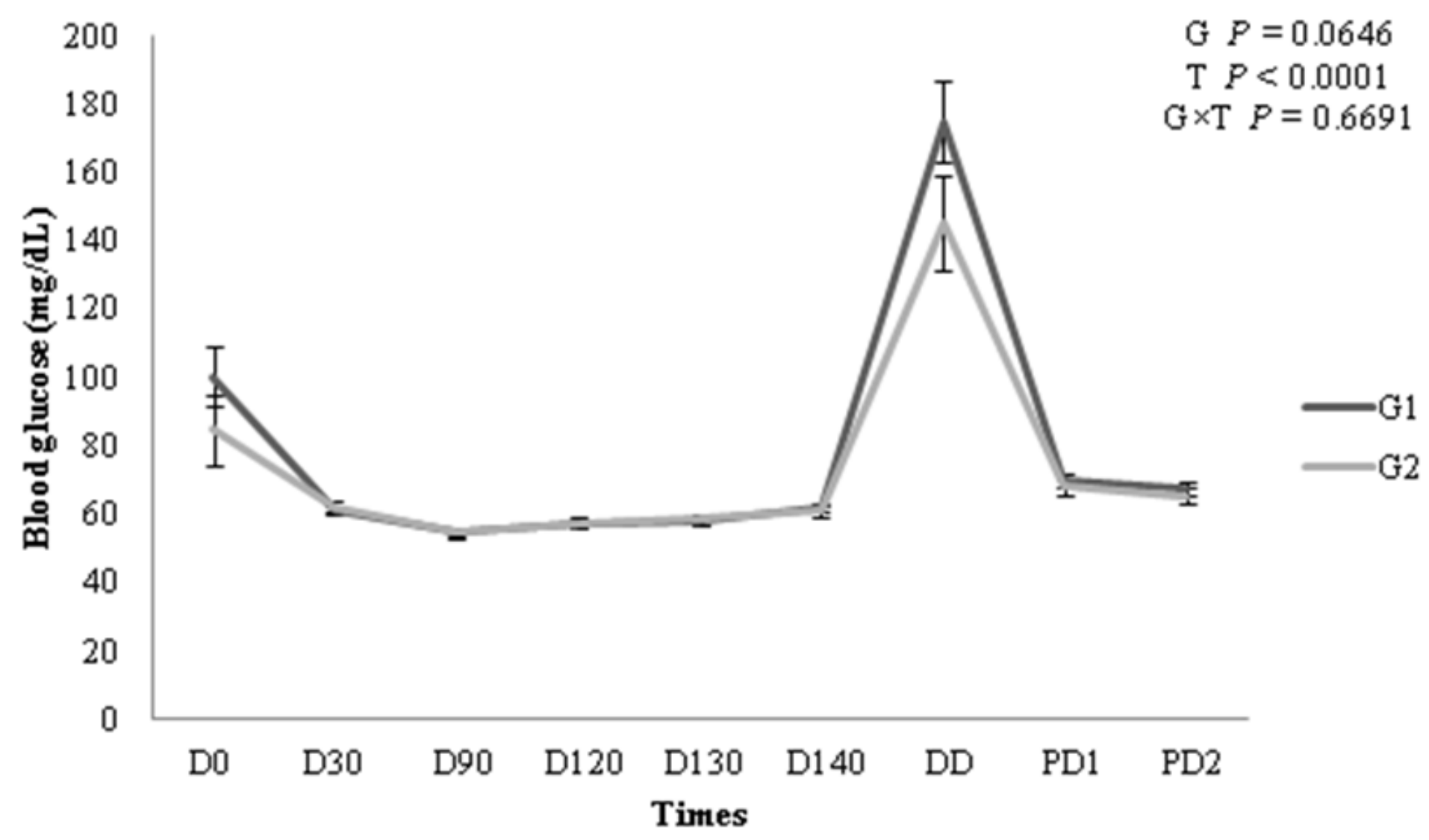

Figure 2

Blood glucose concentration (mg/dL) of Dorper ewes from single (G1) and twin pregnancy (G2) at nine experimental sample times. Data presented as means \pm standard errors. $G=$ group effect; $T=$ time effect; $\mathrm{G} \times \mathrm{T}=$ group and time interaction. 


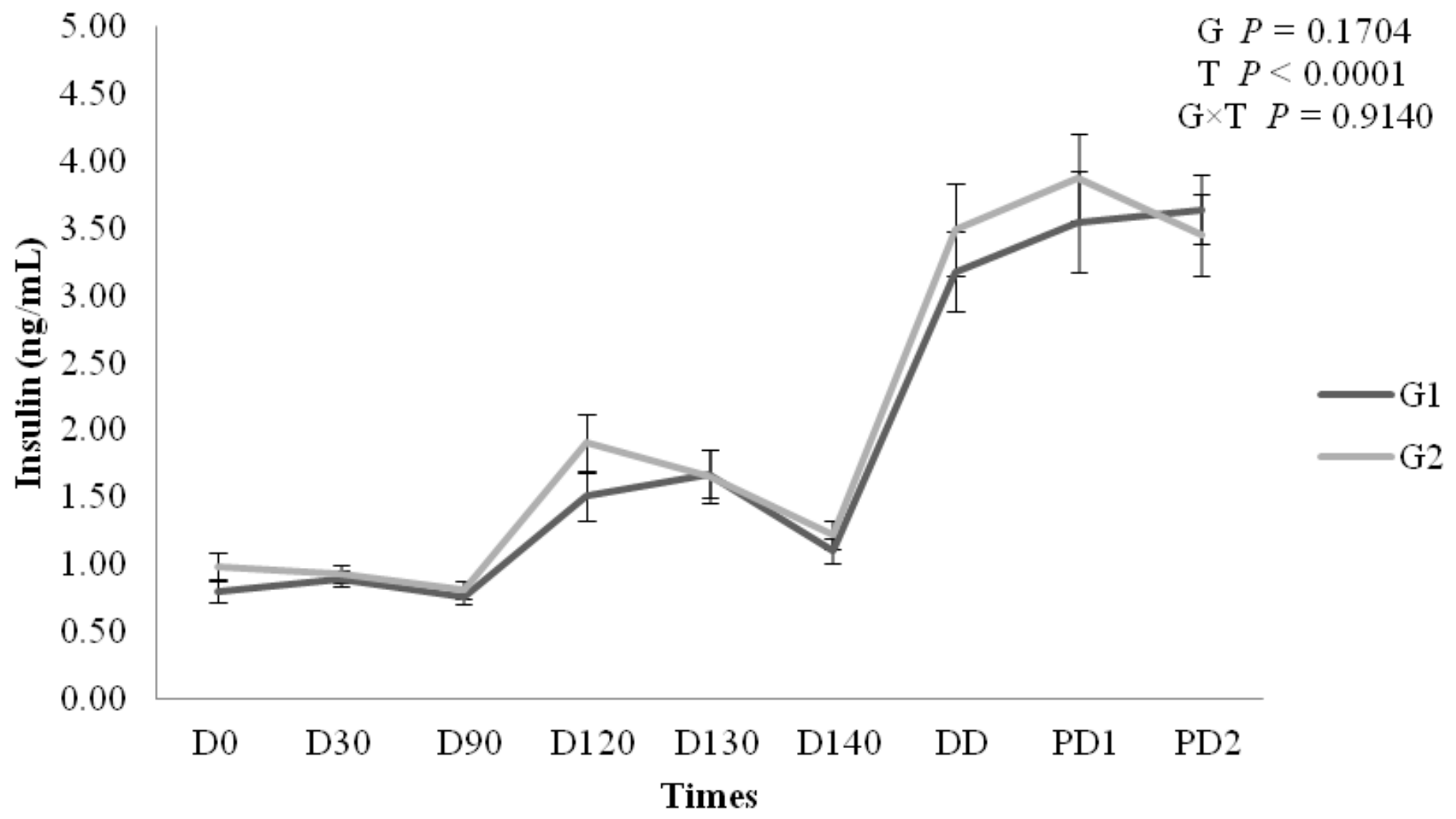

Figure 3

Insulin concentrations $(\mathrm{ng} / \mathrm{mL})$ of Dorper ewes from single (G1) and twin pregnancy (G2) at nine experimental sample times. Data presented as means \pm standard errors. $\mathrm{G}=$ group effect; $\mathrm{T}=$ time effect; $\mathrm{G} \times \mathrm{T}=$ group and time interaction. 


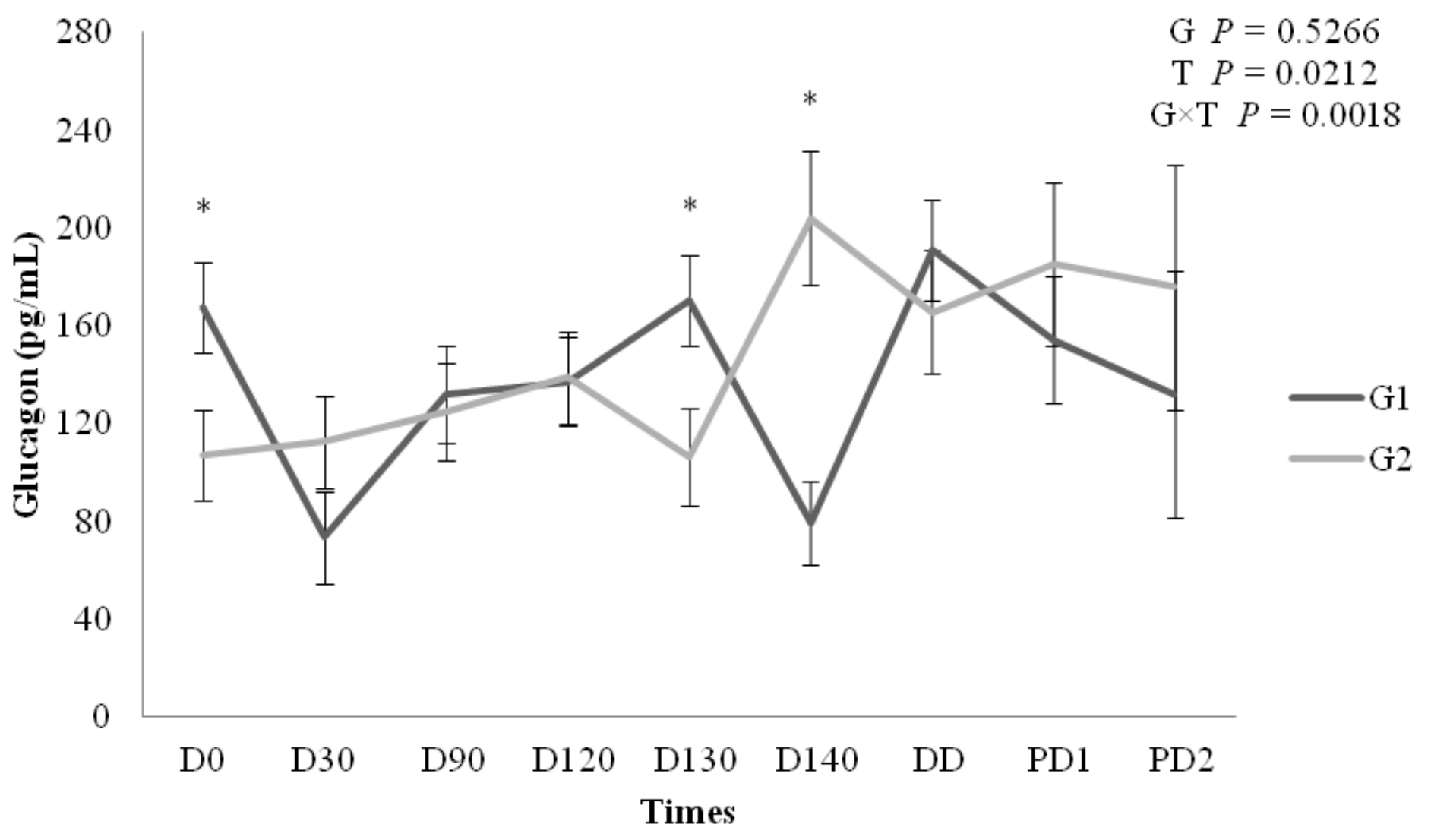

Figure 4

Glucagon concentration ( $\mathrm{pg} / \mathrm{mL}$ ) of Dorper ewes from single (G1) and twin pregnancy (G2) at nine experimental sample times. Data presented as means \pm standard errors. $G=$ group effect; $T=$ time effect; $\mathrm{G} \times \mathrm{T}=$ group and time interaction. *Difference between the groups $\mathrm{P} \leq 0.05$. 


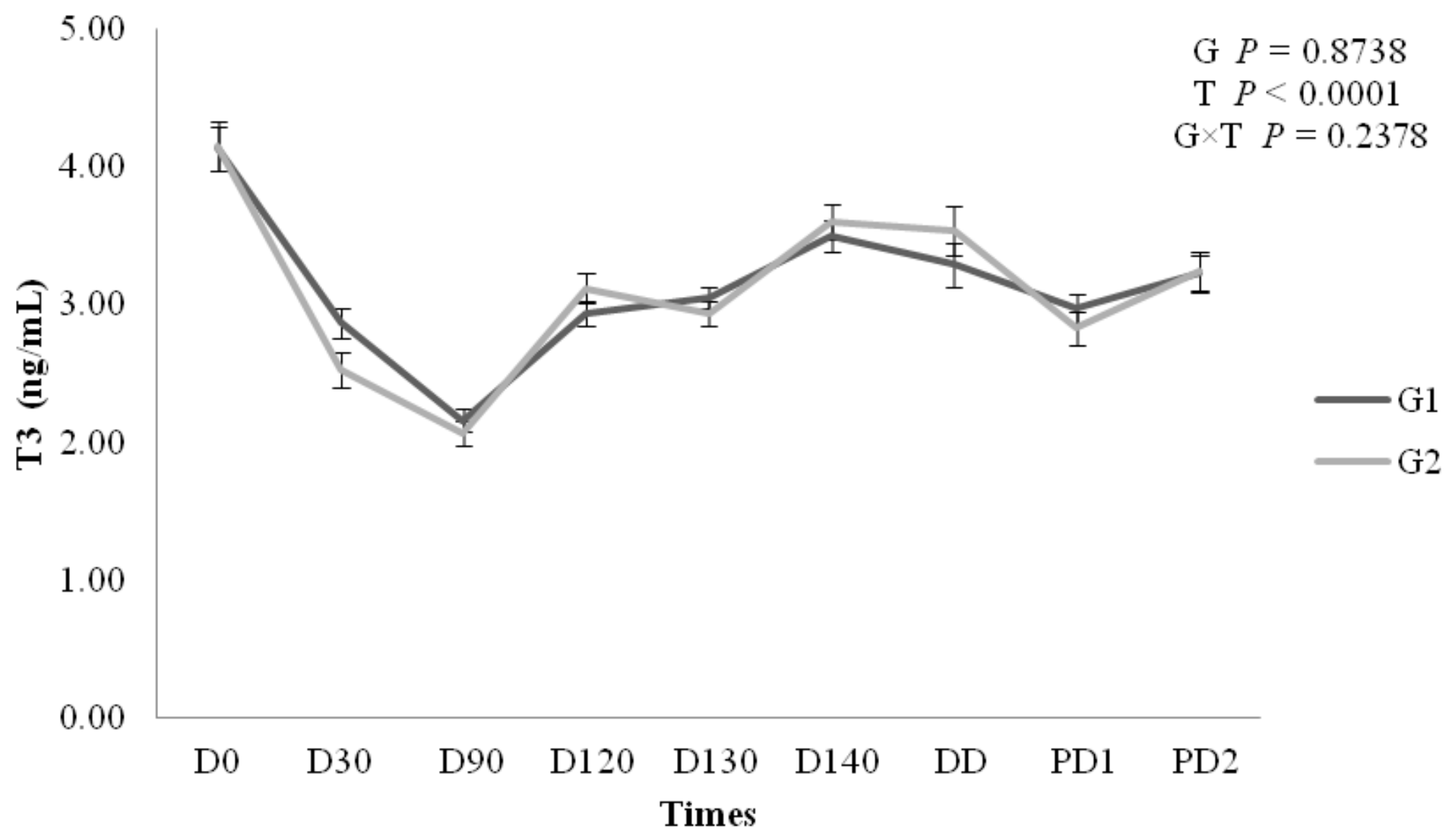

Figure 5

T3 concentration ( $\mathrm{ng} / \mathrm{mL}$ ) of Dorper ewes from both single (G1) and twin pregnancy (G2) at nine experimental sample times. Data presented as means \pm standard errors. $G=$ group effect; $T=$ time effect; $\mathrm{G} \times \mathrm{T}=$ group and time interaction. 


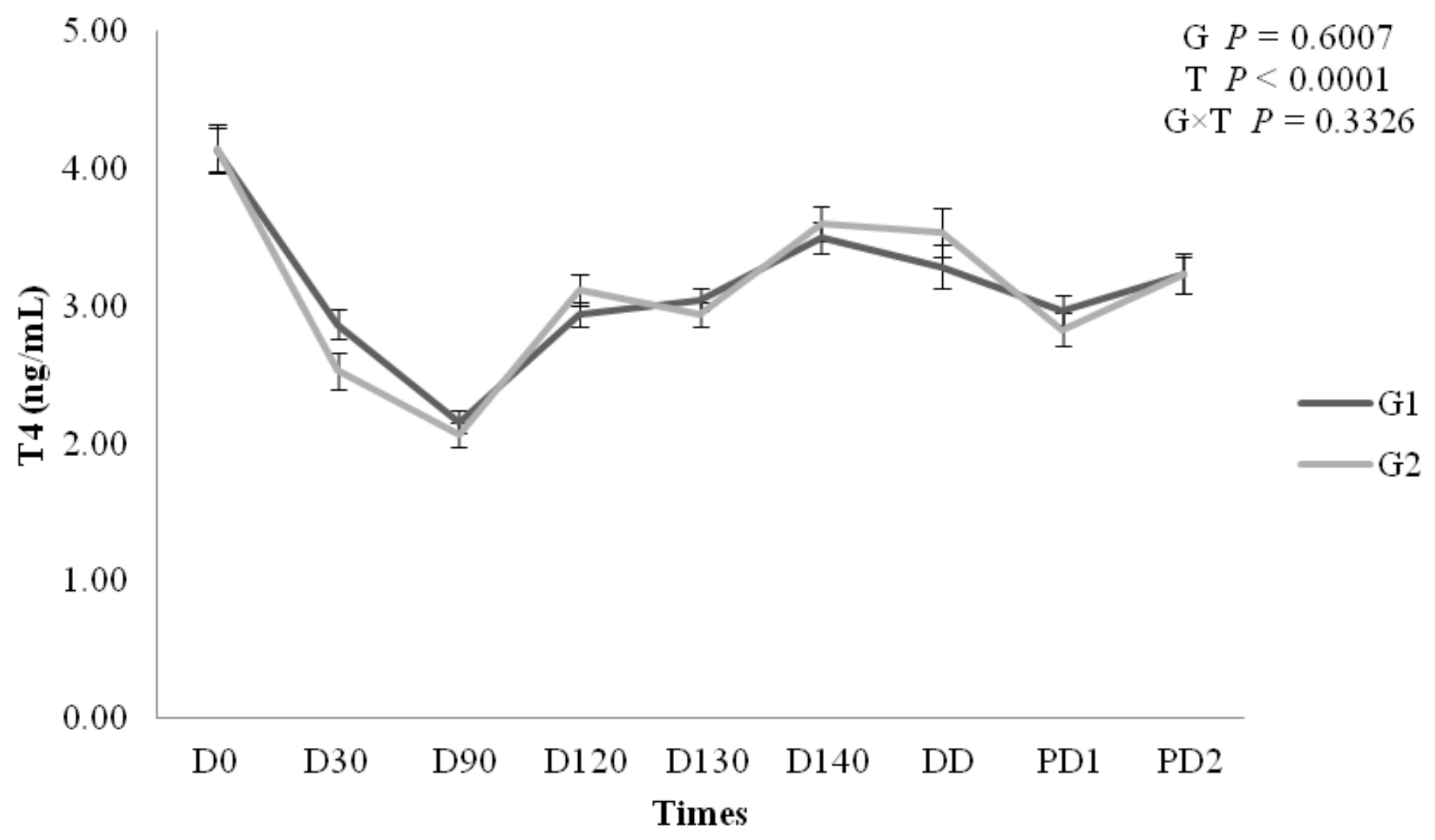

Figure 6

T4 concentration ( $\mathrm{ng} / \mathrm{mL}$ ) of Dorper ewes from both single (G1) and twin pregnancy (G2) at nine experimental sample times. Data presented as means \pm standard errors. $\mathrm{G}=$ group effect; $\mathrm{T}=$ time effect; $\mathrm{G} \times \mathrm{T}=$ group and time interaction . 


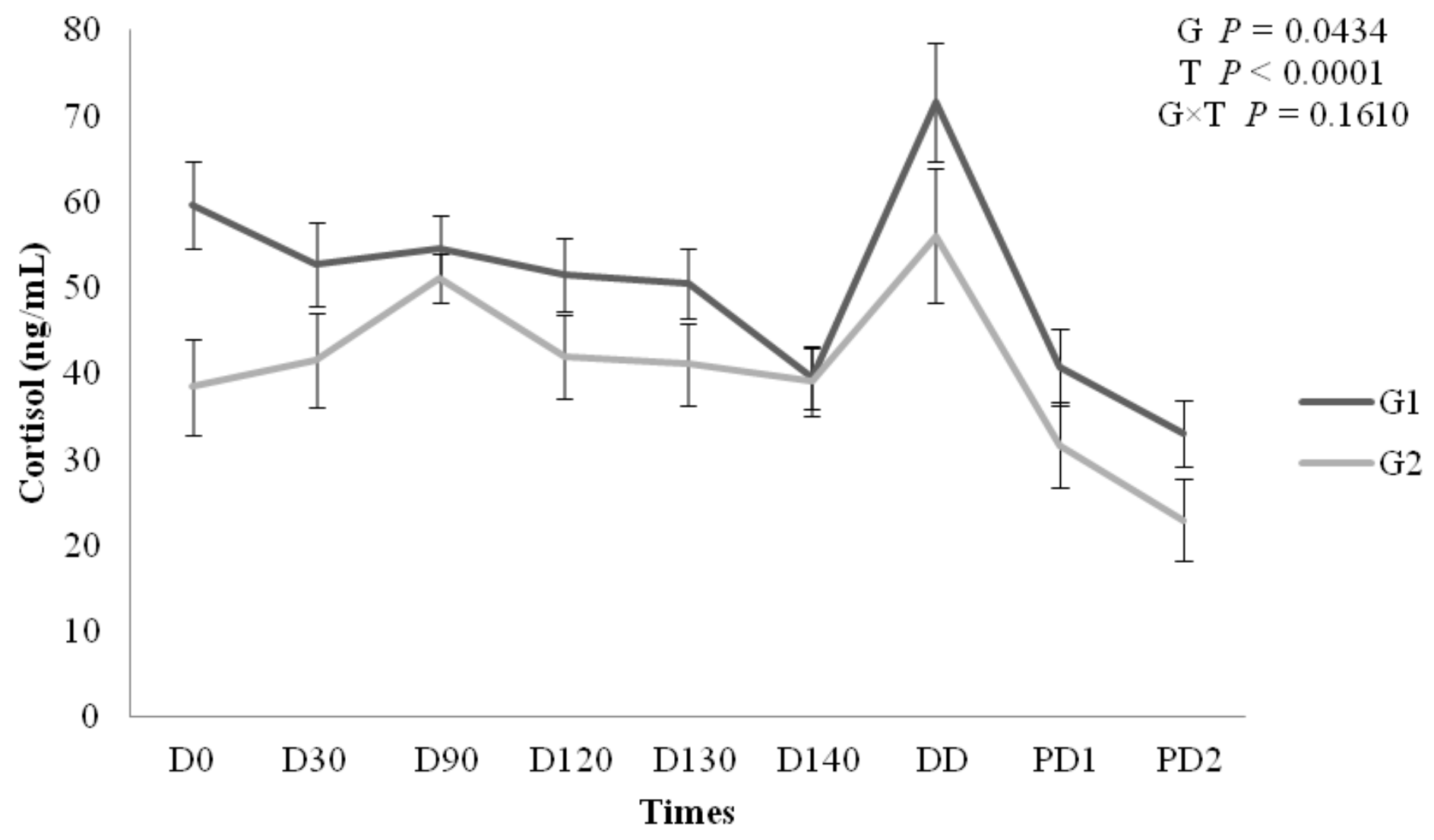

Figure 7

Cortisol concentration $(\mathrm{ng} / \mathrm{mL}$ ) of Dorper ewes from both single (G1) and twin pregnancy (G2) at nine experimental sample times. Data presented as means \pm standard errors. $G=$ group effect; $T=$ time effect; $\mathrm{G} \times \mathrm{T}=$ group and time interaction. 


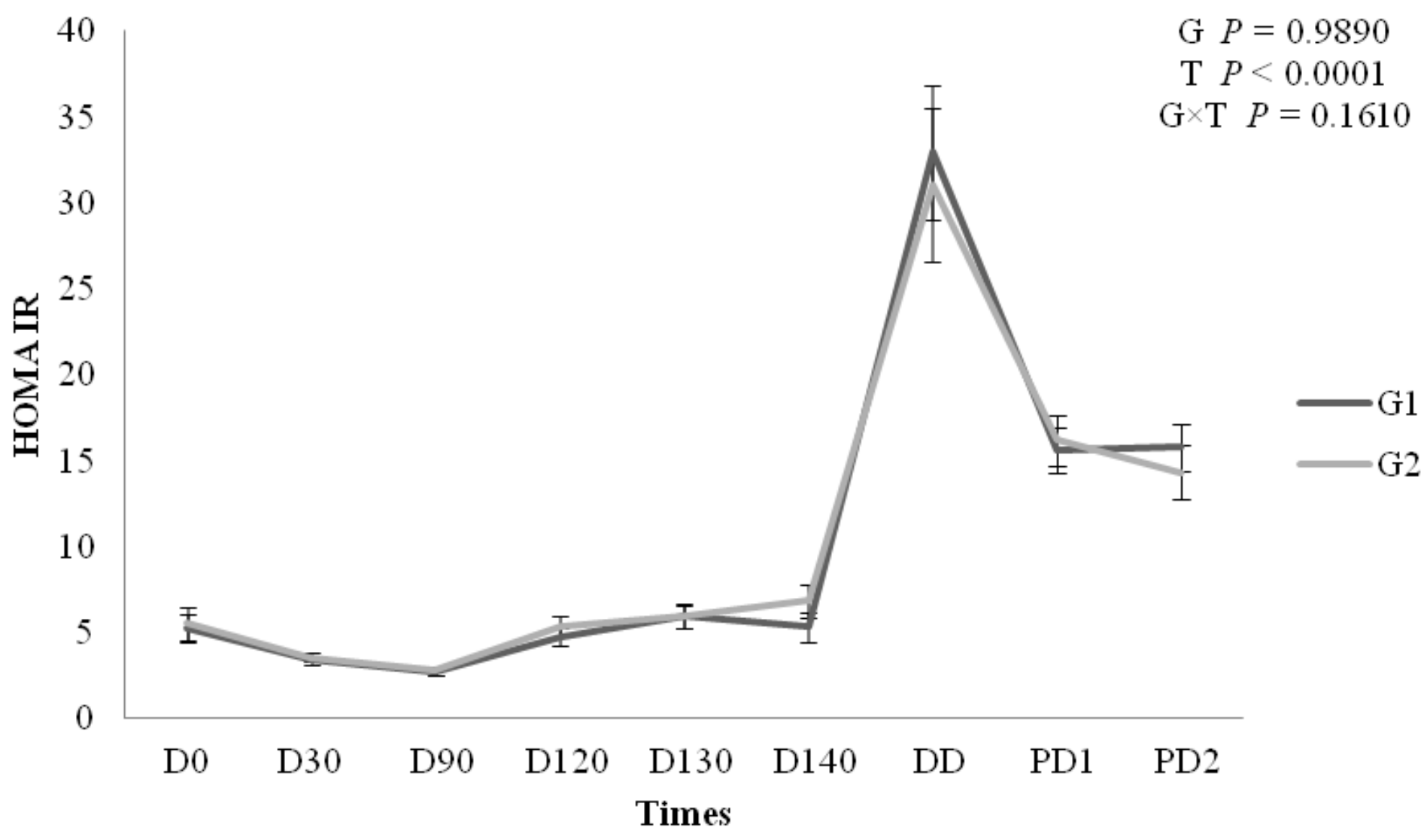

Figure 8

HOMA IR of Dorper ewes from both single (G1) and twin pregnancy (G2) at nine experimental sample times. Data presented as means \pm standard errors. $\mathrm{G}=$ group effect; $\mathrm{T}=$ time effect; $\mathrm{G} \times \mathrm{T}=$ group and time interaction.

\section{Supplementary Files}

This is a list of supplementary files associated with this preprint. Click to download.

- CertificateofeditingBINTA4.pdf 